VANĚK, Z., DoLežILOVÁ, L. \& ŘEHÁČEK, Z. (1958). J. gen. Microbiol. 18, 649-657

\title{
Formation of a Mixture of Antibiotic Substances including Antibiotics of a Polyene Character, by Strains of Actinomycetes Freshly Isolated from Soil Samples
}

\author{
BY Z. VANĚK, L. DOLEŽILOVÁ AND Z. ŘEHǍČKK \\ Institute of Biology, Czechoslovak Academy of Science, Prague, Czechoslovakia
}

SUMMARY : Of a total of 739 actinomycetes freshly isolated from soil samples from China, $515(69.7 \%)$ were antibiotically active. Their antibiotic spectrum was determined against 14, test micro-organisms, including bacteria, yeasts and fungi, and 386 of them were characterized by paper chromatography using agar blocks, by behaviour on agar plates incorporating ion-exchange resins and by u.v. absorption spectrum (to detect polyene substances). Of these strains, $195(50.5 \%$ ) produced a mixture of antibiotics of both polyene and non-polyene type. On the basis of these results the active strains have been classified in various ways.

Most early studies of the incidence of antibiotic properties in actinomycetes were concerned with antibacterial action (Nakhimovskaya, 1937; Krasilnikov \& Koreniako, 1939; Waksman, Horning, Welsch \& Woodruff, 1942; Welsch, 1942 ; Aiso, Arai, Yanagisawa \& Nakajima, 1949; Rouatt, Lechevalier \& Waksman, 1951), and only occasionally showed an interest in antifungal action (Alexopoulos, Arnott \& McIntosh, 1938, 1941; Alexopoulos \& Herrick, 1942; Meredith, 1944). In recent years greater interest has been evinced in the study of antifungal polyene antibiotics, which are distinguished by a characteristic u.v. absorption spectrum (Utahara, Okami, Nakamura \& Umezawa, 1954; Vining, Taber \& Gregory, 1955; Pledger \& Lechevalier, 1956; Ball, Bessel \& Mortimer, 1957).

It was found early on that the production of antibiotic substances by actinomycetes was not species specific. Under different conditions, a number of stains could produce not one, but several different antibiotics (Perlman, 1953). The ability of actinomycetes to produce a number of antibiotics simultaneously was originally regarded as exceptional, but during the past few years several reports have appeared on the production of mixture of antibiotics by actinomycetes in submerged fermentation, chiefly from Japanese laboratories (e.g. Aiso, 1950; Hosoya, Komatsu \& Sonoda, 1951; Takahashi, 1952, 1953; Kikuchi, 1955; Maeda el al. 1956; Nakazawa \& Shibata, 1953; Ueda \& Umezawa, 1956. The present authors concentrated primarily on screening actinomycetes producing a mixture of antibacterial and antifungal substances.

\section{METHODS}

Experimental procedure. Strains of actinomycetes were isolated from samples of Chinese soil by a centrifugation method (Řeháček, 1956). This method involved $20 \mathrm{~min}$. centrifugation of a suspension of a sample of the soil at a relative 
centrifugal strength of $904 \mathrm{~g}$ at the surface and $1609 \mathrm{~g}$ at the bottom and thus removed the micro-organisms accompanying the actinomyces contained in the sample of the soil and excluded their influence on the culturing plates. The centrifugation method made it possible to obtain within 10 days colonies of pure cultures of actinomycetes, which could be re-inoculated direct from the first culture medium and might be used for further study. In this way the tedious purification of strains was done away with, so that influence on the isolated actinomycetes by culturing under laboratory conditions was minimal as compared with present isolation methods.

The isolated strains were grown on solid medium in Petri dishes for 5-8 days. Agar blocks were cut and used for determining the antibiotic spectrum, for characterizing by paper chromatography and for determining the ionic character of the antibiotic substances secreted. The rest of the medium was extracted and tested for the presence of polyenes by u.v. absorption. The visual appearance of the pigment formation was recorded. Thus it was possible to study the production and basic properties of antibiotic substances from a single Petri dish culture.

Media and cultivation. The actinomycetes were maintained on glucose potato agar slopes. Petri dish cultures, each $12 \mathrm{~cm}$. dish, contained $30 \mathrm{ml}$. medium of the following composition $(\%, w / v)$ : glucose 1 , starch $1 \cdot 5$, corn steep 0.5 (dry weight), $\left(\mathrm{NH}_{4}\right)_{2} \mathrm{SO}_{4} 0.35, \mathrm{NaCl} 0.5, \mathrm{CaCO}_{3} 0.5$, agar 2 (Ševčík \& Podojil, 1957; Ševčík, Podojil \& Vrtišková, 1957), selected as the most satisfactory from among a large number of media tested. The organism was evenly inoculated over the whole surface of the medium.

Test bacteria were maintained on meat-infusion peptone agar, but for determining the antibiotic spectrum, they were grown at $32^{\circ}$ on a nutrient medium containing $(\%, w / v)$ : peptone 0.5 , yeast autolysate 0.32 and agar 1.5 .

Test yeasts and fungi were maintained, and cultured during the experiment, at $28^{\circ}$ on a medium containing $(\%, w / v)$ : malt extract $0 \cdot 6$, yeast extract $0 \cdot 3$, glucose 1 , peptone 0.5 and agar 1.5 .

Determination of the antibiotic spectrum. The authors used the agar block method of Ishida, Shiratori, Okamoto \& Miyazaki (1951). Agar blocks $8 \mathrm{~mm}$. in diameter were cut from Petri dish cultures and placed in wells in an inoculated agar medium in glass dishes measuring $35 \mathrm{~cm} . \times 35 \mathrm{~cm}$. One dish held 100 blocks. Incubation was for $20 \mathrm{hr}$. except that with Alternaria solani and Fusarium nivale, when $48 \mathrm{hr}$. was used. After incubation the inhibition zones were measured.

The following test micro-organisms were used: Bacillus subtilis, Staphylococcus aureus, Sarcina lutea, Escherichia coli, Pseudomonas aeruginosa, Serratia marcescens, Candida albicans, Saccharomyces cerevisiae, Penicillium duclauxi, Asperigillus niger, Rhizopus nigricans, Fusarium nivale, Alternaria solani and Trichoderma sp., all from the collection of the Czechoslovak Academy of Science.

Determination of Character of antibiotics. Character of antibiotics was determined by the paper chromatography method elaborated by Ševčík et al. (1957). Agar blocks from Petri dish cultures of the actinomycete were placed on strips of chromatographic paper measuring $1 \mathrm{~cm} . \times 18 \mathrm{~cm}$. After allowing 
$30 \mathrm{~min}$. for diffusion the papers were developed in a system of ten solvents: distilled water, $3 \% \mathrm{NH}_{4} \mathrm{Cl}, 100 \%$ methanol, $100 \%$ acetone, ethylacetate saturated with water, $n$-butanol saturated with water, diethyl ether saturated with water, chloroform, benzene and light petroleum.

When developed, the strips of chromatographic paper were placed on agar medium in glass plates measuring $35 \mathrm{~cm} . \times 35 \mathrm{~cm}$.

Test micro-organisms suitable for biological investigation were selected on the basis of the antibiotic spectrum, In some actinomycetes, production of a mixture of antibiotics could be deduced from the results of biological investigation of the summarized papergram, from the formation of double inhibition zones and from the very broad antibiotic spectrum. In such cases two or more test micro-organisms were used for the biological investigation of the summarized papergram.

Assay of ionic character. Agar blocks with the culture of actinomycetes were placed in the basic agar medium, over which an agar medium containing cation exchange resin ROA (Severa, Pecák \& Hoffman, 1954) or Fluka STG anion exchange resin (A.G. St Gallen) was poured. Agar medium inoculated with a test micro-organism was then poured over the agar medium containing ion exchange resin. The results were evaluated by comparing the averages of inhibition zones obtained after $18 \mathrm{hr}$. incubation at $37^{\circ}$ in the medium containing ion exchange resin and the averages of inhibition zones in the control part of the plate containing no ion exchange resin. This method was elaborated by Ševčík \& Podojil (1957).

Detection of substances of a polyene character. The agar medium remaining after the previous tests was ground, washed with acetone and this extract was dried until completely dry. The u.v. absorption spectrum of an ethanolic extract of the residue was then examined.

\section{RESULTS}

\section{Effect of the actinomycetes on individual test micro-organisms}

Antibiotic activity was detected in $515(69.9 \%)$ of 739 strains of actinomycetes recovered from 115 soil samples. The percentage of strains active against various Gram-positive and Gram-negative bacteria is given in Fig. 1, and against yeasts and fungi in Fig. 2. From Fig. 1 it will be seen that groups C and B contained actinomycetes inhibiting both Gram-positive and Gram-negative bacteria. The percentage of strains inhibiting only Gram-positive bacteria is larger, however. Figure 2 shows that group D, i.e. with inhibition zones of 31-40 mm., contained actinomycetes inhibiting Saccharomyces cerevisiae, Rhizopus nigricans and Fusarium nivale. Group C, with inhibition zones of 21-30 mm., included strains inhibiting all the test micro-organisms with the exception of Alternaria solani. Although Rhizopus nigricans was inhibited by a large number of weakly active strains $(39 \%)$, it was inhibited by only a small proportion of actinomycetes with medium activity (3.3\%). 


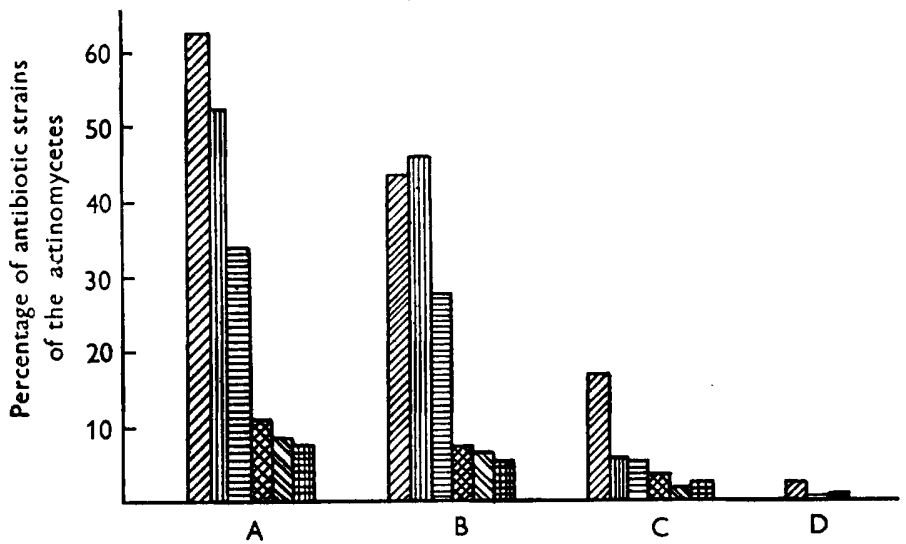

Activity against Gram-positive and Gram-negative bacteria

Fig. 1. The percentage of strains of the actinomycetes active against various Gram-positive and Gram-negative bacteria. A : percentage of strains showing activity of any degree; $B$, percentage of strains showing weak activity, diameter of inhibition zone $10-20 \mathrm{~mm}$.; $\mathrm{C}$, percentage of strains showing moderate activity, diameter of inhibition zone 21$30 \mathrm{~mm}$.; D, percentage of strains showing strong activity, diameter of inhibition zone 31-40 $\mathrm{mm}$. The diameter of the inhibition zone includes the central agar plug of a diameter of $8 \mathrm{~mm}$. $\mathbb{Z}$, Sarcina; 目, Staphylococcus aureus; $\mathbb{N}$, Pseudomonas; 血, Bacillus subtilis; E. coli; ; Serratia.

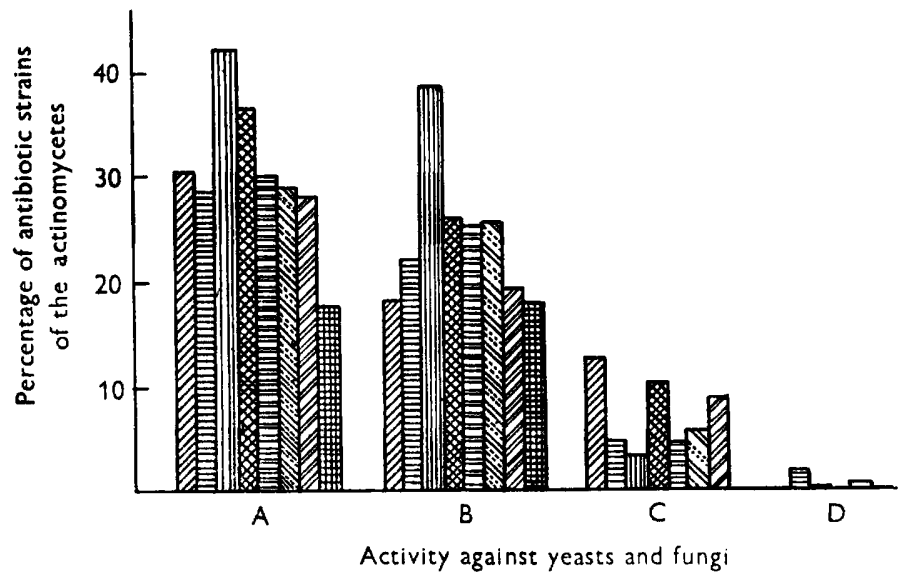

Fig. 2. The percentage of strains of the actinomycetes active against various yeasts and fungi. A, percentage of strains showing activity of any degree; $B$, percentage of strains showing weak activity, diameter of inhibition zone $10-20 \mathrm{~mm}$.; $\mathrm{C}$, percentage of strains showing moderate activity, diameter of inhibition zone $21-30 \mathrm{~mm}$.; $\mathrm{D}$, percentage of strains showing strong activity, diameter of inhibition zone $31-40 \mathrm{~mm}$. The diameter of the inhibition zone includes the central agar plug of a diameter of $8 \mathrm{~mm}$. Vandida; 证, Rhizopus; 目, Fusarium; $\mathbb{Z}$, Trichoderma; 其, Saccharomyces; R, Penicillium; Aspergillus; , Alternaria. 


\section{Action of actinomycetes on groups of test micro-organisms}

In view of the fact that the recently described group of polyene antibiotics is active against yeasts and fungi, but not against bacteria, and as the number of known antibiotics with an antibacterial and antifungal effect is very small, it can already be inferred from the results of this part of the work, as Fig. 3 shows, that a large number of the actinomycete strains in the present series produces a mixture of antibiotic substances.

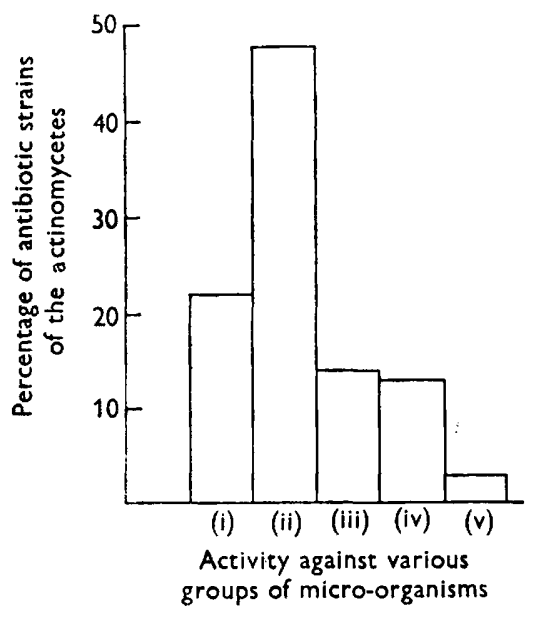

Fig. 3

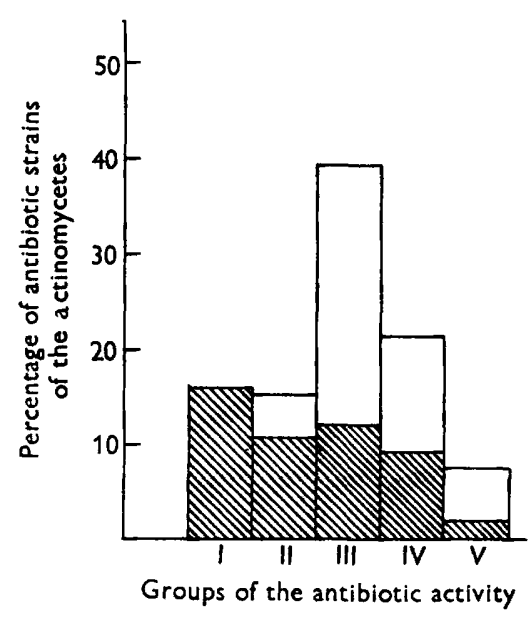

Fig. 4

Fig. 3. Division of the antibiotic actinomycetes into five main groups, according to their general effect against Gram-positive bacteria (i); against Gram-positive bacteria, yeasts and fungi (ii); against Gram-positive bacteria, Gram-negative bacteria, yeasts and fungi (iii); against yeasts and fungi (iv); and against Gram-positive and Gram-negative bacteria (v).

Fig. 4. Classification of the antibiotic activity of 386 of the active actinomycetes into the five main groups, proposed by Waksman \& Lechevalier (1953). Shaded parts of columns show a simultaneous production of antibiotics of polyene character.

Rough classification of antagonistic strains according to the character of the antibiotics and the percentage of strains simultaneously producing antibiotics of polyene character

On the basis of the tests described the authors classified the antibiotic activity of 386 of the active actinomycetes into the five main groups proposed by Waksman \& Lechevalier (1953). The results are illustrated in Fig. 4.

\section{Group I}

Strains producing actinomycin, xanthomycin and other antibiotics, also pigments of a quinone or anthocyanin character, the colour of which depends on the nature of the substrate (e.g. rhodomycin, thodomycetin, actinorhodine, lithmocidin and ceolicolorin).

The antibiotic substances of this group are soluble in organic solvents but 
only slightly in water. These strains produce yellow, orange or red pigments, and are active chiefly against Gram-positive bacteria and fungi, and only to a very small degree against Gram-negative bacteria.

Figure 4, col. II, shows that from among the total number of antagonistic actinomycetes, $15 \cdot 7 \%$ produced antibiotics belonging to this group; 10.6\% produced a mixture of this type of antibiotic together with an antibiotic or antibiotics of a polyene nature.

\section{Group II}

Actinomycetes producing streptothricin, streptomycin, neomycin and other similar antibiotics.

The antibiotic substances in this group are of a basic character, easily soluble in water but not soluble in the majority of organic solvents. They have antagonistic effect on Gram-positive and Gram-negative bacteria and also on fungi.

It can be seen from Fig. 4, col. III, that $39.3 \%$ of the total number of antagonistic actinomycetes producing antibiotic substances belonged to this group; $\mathbf{1 1 . 9} \%$ produced a mixture of this type of antibiotic together with an antibiotic or antibiotics of a polyene nature.

\section{Group III}

Actinomycetes producing antibiotic substances of a neutral or amphoteric character, e.g. chloramphenicol, chlortetracycline, oxytetracycline and flaveolin, and basic substances of the erythromycin-carbomycin type.

The antibiotic substances in this group are weakly soluble in water and easily soluble in organic solvents. Cultures exert antagonistic effect on Grampositive and Gram-negative bacteria and some are also effective against fungi.

Figure 4, col. IV, shows that of the total number of antagonistic actinomycete strains, $21 \cdot 4 \%$ produced antibiotic substances belonging to this group. In addition, $\mathbf{9 \cdot 3} \%$ produced substances of a polyene character.

\section{Group IV}

Actinomycetes strongly active against yeasts and less effective against fungi. It can be seen from Fig. 4, col. V, that of the total number of antagonistic actinomycetes, $\mathbf{7 \cdot 3} \%$ produced antibiotics belonging to this group. At the same time, $1 \cdot 8 \%$ produced polyene antibiotics.

\section{Group V}

Strains of actinomycetes producing substances of a polyene character, with characteristic absorption spectra in u.v. light. These strains exhibit marked antagonistic activity against fungi and are not effective against bacteria.

Fig. 4, col. I, shows that $16.3 \%$ of the total number of actinomycetes produced polyene antibiotics only; $34.2 \%$ produced polyene antibiotics together with antibiotic substances of other groups. Of the total number of 195 strains of actinomycetes which produced antibiotics of a polyene character, 175 
produced hepataenes, one strain hexaene, five strains pentaenes, six strains tetraenes, six strains a mixture of heptaenes and pentaenes and two a mixture of hexaenes and tetraenes.

\section{DISCUSSION}

In these experiments almost $70 \%$ of freshly isolated actinomycetes had an antagonistic effect. In the literature the figures range from 10 to $60 \%$, depending on the methods of testing and the nutrient media. A further factor which influences the number of antagonistic strains detected is marked lability of productive capacity. Thus under laboratory conditions, strains of actinomycetes often lose their ability to produce antibiotic substances after a few subcultures. In the present case this is unlikely to have occurred since all tests were always made from a single Petri dish culture constituting the third subculture after isolation.

A high proportion of freshly isolated strains produce substances of a polyene character as well as other antibiotics. This finding is significant, both from the aspect of methods and from the theoretical point of view. Thus the results of a first screening based on the antibiotic spectrum, solubility and antibiotic properties must be interpreted with great caution, and the possibility that a given strain may produce a mixture of antibiotics must always be taken into account. It should be emphasized that the authors concentrated on the problem of the distribution of strains producing a mixture of non-polyene and polyene antibiotics, which are easily distinguished from one another. The possibility of determining other types of antibiotic mixtures was not investigated.

The results of the work are in agreement with those of Ball el al. (1957) in that the majority of antifungal antibiotics found were also of a polyene character. They differ, however, in the proportional distribution of the individual groups. In the findings of Ball et al. (1957), the largest group was that of the tetraenes, while in the present experiments the most numerous were the heptaenes, in agreement with Pledger \& Lechevalier (1956).

From the incidence of mixture of antibiotics in the individual groups, it is seen that the strains producing polyenes as well as other antibiotics are most numerous in the second group (actinomycins, rhodomycins, rhodomycetin, lithmocidin, etc.) and in the fourth group (antibiotics of the type of tetracycline and erythromycin-carbomycin). It is assumed that this is not a chance phenomenon and that it indicates a definite biogenetic relationship between these antibiotics.

Actinomycetes producing a mixture of antibiotic substances with an antifungal and an antibacterial action are doubtless better equipped for the struggle for existence under the complex competitive conditions which exist among soil microflora. It may be presumed that the formation of mixtures of antibiotic substances is a regular phenomen caused by the interaction of soil microflora and that antibiotic substances are not a chance pathological products of microbial metabolism. 
The authors wish to express their thanks to the following: to Academician P. Němec, Lecturer on Yeast Chemistry at the University College of Chemical Engineering, Bratislava, for the samples of Chinese soil; to Academician I. Málek, Director of the Institute of Biology, and to Dr V. Ševčik for expert advice during research: to B. Hromádková, J. Nohavová, L. Pokorná and L. Kubálová for technical assistance.

\section{REFERENCES}

Aiso, K. (1950). 55th Meeting of Japan Antibiotic Research Association, September. Aiso, K., Arai, T., Yanagisawa, F. \& Nakajima, M. (1949). Studies on the distribution of actinomycetes and their antagonistic strains in Japanese soils. J. Antibiot. A, 2, 240.

Alexopoulos, C. J., Arnotr, R. \& McIntosh, A. U. (1938). Studies in antibiosis between bacteria and fungi. Ohio $J$. Sci. 38, 221.

Alexopoulos, C. J., Arnott, R. \& McIntosh, A. U. (1941). Studies in antibiosis between bacteria and fungi. II. Species of actinomyces inhibiting the growth of Colletotrichum gloeosporoides Penz. in culture. Ohio J. Sci. 41, 425.

Alexopoulos, C. J. \& Herrick, J. A. (1942). Studies in antibiosis between bacteria and fungi. III. Inhibitory action of some actinomycetes on various species of fungi in culture. Bull. Torrey bot. Cl. 69, 257.

Ball, S., Bessel, C. J. \& Mortimer, A. (1957). The production of polyenic antibiotics by soil streptomycetes. J.gen. Microbiol. 17, 1, 96.

Hosoya, S., Komatsu, N. \& Soneda, M. (1951). Rotaventin, an antifungal agent, isolated from mycelium Str. reticuli. Jap. J. exp. Med. $21,279$.

Ishida, N., Shiratori, N., Okamoto, S. \& Miyazaki, J. (1951). Studies on the antibiotic substances from actinomycetes. J. Antibiot. A, 4, 505.

KInUchi, K. (1955). Antibiotics from Streptomyces sp. no. E212. J. Antibiot. $A, 5,145$.

Krasilnikov, N. A. \& Koreniako, A. J. (1939). Bactericidal substances of actinomycetes (in Russian). Microbiology, Moscorw, 8, 673.

Maeda, K., OoI, K., Kosaka, H., Lin Wang, E. \& Umezawa, H. (1956). On the simultaneous production of an actinomycin and an eurocidin group antibiotic. J. Antibiot. A, 3, 125.

Meredith, C. H. (1944). Antagonism of actinomyces to Fusarium oxysporum cubense. Phytopathology, 34, 426.

Nakazawa, K. \& Shibata, H. (1953). On eurocidin. Report at the meeting of Japan Antibiotic Research Association, September.

Nakhimovskaya, M. J. (1937). Antagonism between actinomycetes and soil bacteria (in Russian). Microbiology, Moscow, 6, 131.

Periman, D. (1953). Physiological studies on the actinomycetes. Bot. Rev. $19,46$.

Pledger, R. A. \& Lechevalier, A. (1956). Survey of the production of polyenic substances by soil streptomycetes. Antibiot. Annual, p. 249.

ŘEHÁČEK, Z. (1956). Stanovení poětu zárodků sporulujících aktinomycet v půdĕ a jejich isolace. Čsl. mikrobiol. $1,129$.

RovatT, J. W., Lechevalier, H. \& Waksman, S. A. (1951). Distribution of antagonistic properties among actinomycetes, isolated from different soils. Antibiot. \& Chemother. 1, 186.

ŠEv̌̌́r, V. \& PoDoJIL, M. (1957). Orientierende Bestimmung des Ionencharakters der Antibiotika mit Hilfe von Plattentesten. Naturwissenschaften, 44, 93.

Ševěík, V., Podojil, M. \& Vrtiškova, A. (1957). Použití papírové chromatografie při výzkumu nových antibiotik. Čsl. mikrobiol. $2,175$.

Severa, Z., Pecák, V. \& Hofrman, J. (1954). Průmyslová isolace látek na měničích iontů. Chem. prümysl. 4, 223.

TAKAHASHi, I. (1952). Antiyeast factors produced by the '1st group' actinomyces. J. Antibiot. A, 4, 188. 
Takahashi, I. (1953). A new antifungal substance Flavacid. Studies on the antibiotic substances from actinomyces. XXVII. J. Antibiot. A, 3, 117.

UEDA, M. \& UMEZAWA, H. (1956). Observation on the simultaneous production of actinoleukin and trichomycin group antibiotics by a streptomyces. J. Antibiot. A, 2, 86 .

Utahara, R., Okami, Y., Nakamura, S. \& Umezawa, H. (1954). On a new antifungal substance, Mediocidin, and other antifungal substances of streptomyces with three characteristic absorption maxima. J. Antibiot. A, 8, 120.

Vining, S. C., Taber, W. A. \& Gregory, F. Y. (1955). The candidin-candicidin group of antifungal antibiotics. Antibiot. Ann. p. 980.

Waksman, S. A., Horning, E. S., Welsch, M. \& Woodruff, H. B. (1942). Distribution of antagonistic actinomycetes in nature. Soil Sci. 54, 281.

Waksman, S. A. \& LeChevalier, A. (1953). Guide to the classification and identification of the actinomycetes and their antibioties. Baltimore. Baillière, Tindall and Cox.

WeLSCH, M. (1942). Bacteriostatic and bacteriolytic properties of actinomycetes. J. Bact. 44, 571 . 